Revista

ACor

das Ietras

\title{
(Re)Construção Mítica de Eva Perón no Romance Santa Evita (1996), de Tomás Eloy Martínez
}

\section{Eva Peron's mythical reconstruction along the novel Santa Evita (1996), by Tomás Eloy Martiner.}

\author{
Josiane Valcarenghi Ribeiro Nantes* \\ Universidade Estadual do Oeste do Paraná, \\ Cascavel, Paraná, Brasil \\ Gilmei Francisco Fleck** \\ Universidade Estadual do Oeste do Paraná, \\ Cascavel, Paraná, Brasil
}

\begin{abstract}
Resumo: Eva Perón é um nome significativo na história política da Argentina. Sua influência surtiu, e continua surtindo, efeito no povo desse país até os dias atuais. "Evita" foi odiada/amada em níveis extremos, tanto que foi considerada uma santa, um mito para muitas pessoas. Tomás Eloy Martínez relê esse passado no romance Santa Evita (1995) - em que narra, pela via da metaficção, como viveu a esposa de Juan Domingo Perón. Nesta obra encontram-se muitos elementos que dão indícios da (re)mitificação de Eva, por isso buscamos, aqui, explorar como se deu a (re)construção mitológica de Eva Perón, personagem histórica no romance Santa Evita, traduzido ao português em 1996, de Tomás Eloy Martínez e, ainda, expor quais foram os procedimentos adotados pelo autor que (re)construíram esse mito na escrita híbrida. Utilizamos, como base teórica, as reflexões de Hutcheon (1991) e Fleck (2007; 2011), com relação aos aspectos da metaficção historiográfica; e as de Eliade (1991) e Feijó (1984), nos aspectos referentes à análise do Mito. A proposta de escrita se efetiva a partir da análise bibliográfica e de forma comparativa entre o discurso da história e a escrita ficcional do romance Santa Evita (1996) pela discussão dos elementos utilizados e o caminho percorrido para a (re)construção do mito Eva Perón na escrita metaficcional.
\end{abstract}

Palavras-chave: Santa Evita (1996); (Re)construção Mítica; Eva Perón; Metaficção historiográfica.

\begin{abstract}
Eva Perón is a major name in the political history in Argentina. Her influence impacted, and still continues to impact, the people in this country nowadays. "Evita" was hated and loved in extreme levels that she was considered a saint, a myth for many people. Tomás Eloy Martínez rereads this past in the novel Santa Evita (1995) - in which is narrated, through metafiction, how Juan Domigo Perón's wife lived. In this literary piece there are many elements that indicate the (re)myth-making of Eva Perón, that's why we aim to explore here how the mythological (re)construction of Eva Perón took place, a historical character in the novel Santa Evita, translated into Portuguese in 1996, by Tomás Eloy Martínez and, still, expose the procedures adopted by the writer that (re)built this myth in the hybrid genre. We used, as theoretical background, the reflexions by Hutcheon (1991) and Fleck (2007), in relation to the historigraphic metafictional aspects; the ones by Eliade (1991) and Feijo (1984) in the aspects referring to the myth analysis. The proposal of this paper goes from the bibliographical analysis and the comparative form between the historical discourse and the fictional writing of the novel Santa Evita (1996) through the discussion of the elements used and the path covered for the (re)construction of the myth Eva Perón in the metafictional writing.
\end{abstract}

Keywords: Santa Evita (1996); (Re)mythic construction; Eva Perón; Historiographic metafiction.

* Mestranda no programa de pós-graduação stricto sensu em Letras da Universidade Estadual do Oeste do Paraná Unioeste/Cascavel - Brasil. E-mail: josianevalcarenghi@gmail.com.

** Professor Doutor Universidade Estadual do Oeste do Paraná - Unioeste/Cascavel - Brasil. E-mail: chicofleck@yahoo.com.br. 


\section{O ROMANCE HISTÓRICO/METAFICÇÃO HISTORIOGRÁFICA E A OBRA DE TOMÁS ELOY MARTÍNEZ - SANTA EVITA (1996)}

Eva Perón (1919-1952) foi, e ainda é, um nome que inspira amores e desamores no povo argentino. A figura desta personagem, utilizada tanto literária quando imageticamente, está, na maioria das vezes, acompanhada de uma "aura" mítica.

A atuação histórica desta mulher, que movimentou multidões em sua nação, fez com que surgisse esse ícone lendário em torno a ela. A (re)construção dessa imagem simbólica de Eva Perón é, constantemente, encontrada nas obras em que ela é inserida como personagem ficcional. Por isso, escrever sobre uma personagem histórica de uma forma mágica, lendária, fantasiosa, utilizando-se de elementos históricos e, ainda, recriar a imagem mítica dessa figura político-social argentina com elementos sobrenaturais costurando um ao outro como se realidade e fantasia fossem partes de uma instância maior, exaltando o "real" da vida de Eva Duarte Perón - aguçam, no leitor, a curiosidade em desenredar o processo construtivo da narrativa de Tomás Eloy Martínez (autor e, ao mesmo tempo, narrador da metaficção aqui comentada).

Até o século XIX, antes do advento do cientificismo, não havia separação entre História e Literatura e, assim, o real e o imaginário andavam juntos em muitas escritas de forma que, nos registros daquela época, o humano e o divino, a sociedade e o indivíduo fundiam-se. Paul Veyne (1998, p. 18) nos apresenta uma instigante relação entre essas duas disciplinas, pois sua proposta é a de que "a história é uma narrativa de eventos: todo o resto resulta disso." Portanto, os leitores não têm acesso à outra leitura senão a de um narrador que vai relatar os fatos segundo sua visão, sua linguagem. Logo, ele não passa de um narrador de acontecimentos. Pode-se, desse modo, afirmar que a escrita da história está marcada por subjetividade, e esta é uma característica também da literatura - especialmente do romance.

Literatura e história originaram-se juntas, como partes de um intento de manter a memória coletiva. Com o passar dos anos e o processo de consciência do homem, elas foram se separando, conforme propõe Maestri (2002, p. 38) em seus estudos. Contudo Albuquerque (2013, p. 33), em sua leitura de Weinhardt, mostra-nos que tanto a história quanto ficção se alicerçam num mesmo pilar, já que

[...] a narrativa histórica se constrói sobre fatos reais, a narrativa ficcional sobre fatos imaginários, mas as duas são construções verbais. Quanto ao caráter de ambas enquanto construções verbais, não há o que questionar. Mas no caso da ficção de caráter histórico, também a distinção de conteúdo tende a se atenuar e até a desaparecer de vez, a ponto de muitas vezes o leitor comprometido com catalogações hesitar, se lhe exigem uma resposta imediata à pergunta se está lendo ficção ou história. (WEINHARDT apud ALBUQUERQUE, 2011, p. 14).

Essa fronteira, que marca os limites entre os discursos ficcional e historiográfico, confronta o fazer de um e outro profissional - ficcionista e historiador - e postula que o fato ou objeto para ter valor histórico necessita de historicidade. Baseando-se nos estudos de Gomes (2005), podemos compreender que é essa historicidade que dá 
caráter factual à vivência, em oposição à narratividade que cerca o homem; e, segundo a autora, ela refere-se àquilo que dá valor ao antigo apenas por ser antigo, e não por ter uma qualidade intrínseca diferenciada. Em seus estudos sobre Veyne, a pesquisadora questiona o percentual de formação entre ficcionista e historiador, indaga o quanto há de cada um em sua formação. Suas interrogações ressaltam o comprometimento que ambos necessitam ter para com suas obras.

Jameson (1997, p. 290) propõe uma definição mais abrangente de historicidade, tornando a afirmação de Gomes (2005) quase inviável, pois, para ele, "a historicidade [...] é [...] uma percepção do presente como história", é o distanciamento entre os eventos que dá valor histórico e, portanto, sem historicidade nos fatos não se pode afirmar que algo tenha valor histórico.

Dessa forma, a história que tínhamos como "verdadeira" perde seu valor absoluto na contemporaneidade e pode sofrer mudanças profundas, pois novas perspectivas dos fatos, novas personagens, novos elementos são inseridos e aceitos, tanto no campo da ciência que trata do passado, como no gênero romance histórico, que o ilumina muitas vezes desde as múltiplas perspectivas que seu gênero abrange.

\section{UM JOGO ENTRE “VERDADES E MENTIRAS”}

$\mathrm{Na}$ segunda metade do século XX, a literatura latino-americana, em especial o gênero romance histórico, passa por mudanças estético/estruturais significativas. Seu novo formato de escritura, apresentado, inicialmente, por Aínsa (1988/1991) e, depois, revisado por Seymour Menton (1993), é denominado pela crítica como "novo romance histórico latino-americano". A pesquisadora Antonia Viu (2007, p. 171) cita, em um artigo seu, as dez características que Aínsa afirma serem essenciais para a classificação de uma obra como pertencente à modalidade citada, em seguida, apresenta a reformulação proposta por Menton (1993), que transforma os dez traços iniciais em seis. Dessa reavaliação feita, o apontamento que merece destaque é: "la metaficción o los comentarios del narrador sobre el proceso de creación. [...] frases parentéticas, el uso de la palabra "quizás" o sus sinónimos y notas, a veces apócrifas, al pie de la página” (MENTON, 1993, p. 43). Tais reflexões apontam a alguns traços constituintes da obra de Martínez (1996).

Dessas características apresentadas e discutidas pelos autores sobre a modalidade do novo romance histórico tem-se na atualidade, novas perspectivas. Essas estão evidenciadas nos estudos de Fleck $(2007$; 2011), que discute a respeito da trajetória história e transformacional que o gênero romance histórico tem percorrido. Nesse sentido, apresenta as diferentes fases que se originaram nessa escrita romanesca desde a sua base no romantismo até a atualidade. $\mathrm{O}$ autor citado analisa o processo de formação das distintas modalidades que compõem as fases diferentes da trajetória do gênero, e apresenta uma nova modalidade: o romance histórico contemporâneo de mediação, que amalgama as escritas mais atuais. Essas, segundo Fleck (2007; 2011), já não são passíveis de enquadrar na modalidade do novo romance histórico latino-americano, pois deixam de incorporar os elementos citados pelos pesquisadores anteriores, fazendo uma "mediação" entre o tradicionalismo e a renovação. Desse novo contexto, ainda à luz dos 
estudos de Fleck (2007, p. 158), merecem destaque os romances que se constituem de discursos autorreferenciais que, ao renarrativizar eventos do passado, no presente, constituem-se como metaficções historiográficas. Hutcheon (1991), em seus estudos sobre a Pós-modernidade, apresenta o termo "metaficções historiográficas" para dar conta de obras que se constroem nesse alicerce da metanarração, contudo, deixa claro que nem todas as obras que usam esse tipo de discurso podem ser classificadas como metaficções historiográficas, confirmando isso, Fleck (2007, p. 159) aponta que, além da necessária presença dos recursos autorreferenciais ao longo de toda a narrativa,

[...] o que caracteriza as obras essencialmente de metaficção historiográfica, e que diferenciam tais obras das concebidas dentro da modalidade do novo romance histórico, é, em essência, a profunda autoconsciência com que o narrador exibe e assume o conhecimento de que história e ficção são, ambas, construções discursivas, sistemas de dar sentido ao real.

Portanto, de acordo com o raciocínio acima, a metaficção não é somente uma característica que compõe o conjunto de estratégias de uma narrativa, mas, sim, o arcabouço vital da obra, no qual se estabelece, pela autorreferencialidade, um jogo entre a fronteira do histórico com o fictício, mas, no fim, ambos os discursos estarão atrelados para (re)significar o real pela sua própria essência: a linguagem. Os recursos da metanarração serão os ingredientes que darão sabor a essa mistura.

Fleck (2007) faz uma descrição histórica detalhada do processo evolutivo do gênero romance histórico e suas modalidades. Como resultado de seus estudos, apresenta três fases distintas da trajetória. Essas fases são compostas por 5 modalidades: a clássica e a tradicional, o novo romance histórico e a metaficção historiográfica e o romance histórico contemporâneo de mediação, que expande os resultantes das dez características apontadas por Aínsa e das seis apontadas por Menton. Dentro dessa nova classificação, Fleck (2007, p. 162) exemplifica a metaficção historiográfica com a obra objeto deste estudo e elucida alguns de seus componentes, mencionando:

\begin{abstract}
Nesse romance, [...] encontram-se dois eixos argumentais interrelacionados e interdependentes [...]. Por um lado temos a narrativa da própria escritura do romance, feita em primeira pessoa que busca identificar o narrador desta história com o autor que escreve a obra: Tomás Eloy Martínez. [...] No segundo eixo, aparece o intento de reconstruir a história de Eva Perón. Este eixo caminha em duas linhas temporais - uma volta-se para o passado e outra para o futuro. [...] A obra de Tomás Eloy Martínez se insere dentro dos pressupostos da metaficção historiográfica, apontados por Hutcheon, pois (1991, p. 121), além de constituir-se no sentido global da obra, "[...] ele reinsere os contextos históricos como sendo significantes, e até determinantes, mas ao fazê-lo, problematiza toda a noção de conhecimento histórico".
\end{abstract}

A Metaficção historiográfica, na concepção de Fleck (2007), é uma das modalidades do gênero romance histórico e essa encontra eco forte no romance Santa Evita (1996), de Tomás Eloy Martínez, obra que entrelaça, no enredo, a personagem histórica Eva Perón e a história mágica de um corpo (da mesma) capaz de congregar em torno de si uma multidão, entre adoradores e perseguidores, que são cativados pelo 
cadáver e que, para aproximar-se dela/dele, aceitam qualquer sacrifício. Tudo isso é narrado pela autoprojeção do autor ao universo ficcional - que atua como voz enunciadora do discurso romanesco - ao inserir-se, como personagem, na ficção arquitetada, dando-lhe todos os realces da autorreferencialidade que uma metaficção requer.

Essa classificação da obra literária, inserida no grande contexto das escritas híbridas de história e ficção que compõem o gênero romance histórico, tem como objetivo desmarginalizar o literário, confrontando os fatos ficcionais com a história. Uma outra proposta dessa metaficção para a personagem histórica de Eva Perón, é a de reafirmação do mito "Evita". Isso ocorre pela exploração do narrador de imagens cristalizadas da esposa de Juan Domingo Perón por meio de testemunhos (reais ou fictícios) que tiveram relações diversas com ela. Indivíduos são ficcionalizados e inseridos no romance na forma de personagens de extração histórica ou puramente fictícias que, então, relatam momentos decisivos da vida da protagonista da obra de Martínez, para, assim, tentar (re)construir o caráter desse ícone latino-americano. A autoprojeção de Tomás Eloy participa dos eventos relatados e narra a ficção, vai reinventando a história de Eva. O autor recria os acontecimentos e os adapta à biografia dessa mulher que, para muitos argentinos, é santa, "Santa Evita".

Portanto, essa obra de Martínez, o romance que trata da vida de Eva Perón, é uma obra pós-moderna e faz parte, num contexto maior, do gênero romance histórico, e integra o conjunto latino-americano da modalidade de metaficção historiográfica, conforme defende Fleck (2007). Feitas essas considerações, é hora de começarmos a análise propriamente dita da estrutura/estética da narrativa. Santa Evita (1996) já foi tema de muitos artigos, dissertações e teses, contudo, propõem-se, aqui, uma reflexão sobre algumas das estratégias escriturais-discursivas que Martínez utilizou para (re)construir a imagem mitológica da personagem dentro da obra.

\section{A (RE)CRIAÇÃO DE UM MITO}

Em Santa Evita (1996) existe um sentimento de fatalidade, de final trágico inevitável em volta daquelas personagens que se envolvem com o corpo de Eva. Todas, de certa forma, são atingidas por uma "maldição", e têm suas vidas transformadas por algum feito ruim. No entanto, o aceitam (o corpo) com resignação, desde que possam aproximar-se do cadáver de Evita, situação confirmada pelo diálogo de Tomas Eloy (personagem) com a personagem configurada como a viúva do Coronel Koening: - "A culpada foi Evita - repetiu a viúva. - Todas as pessoas que estiveram com o cadáver acabaram mal. [...]. Se pretende contar essa história, deveria ter cuidado. Assim que começar a contá-la, o senhor também não vai ter salvação.” (MARTíNEZ, 1996, p. 52).

Essa personagem, a viúva de Koening, responsabiliza o cadáver pelo trágico fim da personagem coronel Koening, que foi profundamente afetada, psicologicamente, pela incumbência que recebeu de cuidar da segurança do cadáver. Essa personagem criou uma dependência com relação à presença do corpo de Eva que foi agravada pelo seu alcoolismo e por problemas nervosos. Terminou sua vida sozinha, abandonada pela 
esposa e pelas filhas. O Coronel foi desmoralizado no exército, uma vez que foram descobertas suas tramas para ocultar o corpo de Eva, inclusive de seus superiores, e também por desobedecer às ordens presidenciais. (MARTÍNEZ, 1996, p. 237-242).

Outras personagens também foram atingidas por catástrofes: Eduardo Arancibia, que fez parte da equipe do coronel Koening, encarregado de desaparecer com o corpo, matou a própria mulher num acidente, em um episódio em que o cadáver estava escondido na casa de Arancibia. Um dia quando ele parecia não estar em casa, a esposa tentando descobrir o que ele tanto escondia, foi surpreendida pelo marido que pensou que ela era um ladrão e lhe deu dois tiros. (MARTÍNEZ, 1996, p. 231 - 232). Outro personagem, Milton Galarza, também sob o comando do coronel, teve um acidente que lhe deixou o rosto desfigurado.

$\mathrm{Na}$ narrativa, aqueles que se envolveram indiretamente com o corpo, ou seja, que não estavam tentando ocultá-lo, sofreram consequências fatais, como nesse episódio posterior ao descobrimento do cadáver em Madrid:

Em novembro de 1974, seu corpo foi retirado do túmulo em Madrid e transladado a Buenos Aires. Quando estava em um furgão a caminho do aeroporto de Barajas, dois guardas-civis começaram a discutir por causa de uma dívida de jogo. Quando viraram na avenida General Sanjurjo, em frente aos reservatórios de água, eles se pegaram a tiros e o veículo, descontrolado, bateu na cerca do Real Automóvel Clube. A cabine pegou fogo e os guardas morreram. Apesar da dimensão dos estragos, o ataúde de Evita não sofreu dano algum, nem sequer um arranhão (MARTÍNEZ, 1996, p. 53 e 54).

A explicação que o narrador, Tomás Eloy Martínez, encontra para tantos fatos ruins sucessivos é que "as almas têm sua própria força da gravidade: são avessas às altas velocidades, ao ar livre à ansiedade." (MARTÍNEZ, 1996, p. 54). Com o corpo de Evita acontecia o mesmo, quando o moviam de um lado para outro se "revoltava" e, por um raro fenômeno "sobrenatural", ele se rebelava e todos os seus transgressores sofriam as consequências de seus atos.

Todos esses fatos "sobrenaturais", descritos no decorrer do romance, são como fios de uma tecelagem que forma uma grande tela que é a (re)construção do mito de Eva Perón. Para seguirmos nesse caminho, é necessário entendermos como nasce um mito.

Originalmente o conceito de mito está vinculado às histórias fabulosas dos Deuses, Semideuses e Heróis da mitologia. Mas, em nosso estudo, ampliaremos esse conceito, uma vez que é impossível encontrar uma única definição capaz de sustentar todos os tipos e todas as funções dos mitos em todas as sociedades.

O mito é uma realidade cultural extremamente complexa que pode ser abordada e interpretada através de perspectivas múltiplas e complementares. Por isso adotaremos o conceito formulado por Feijó (1984, p. 12-13) que expressa:

O mito corresponde às crenças de um povo, do conjunto, da comunidade, da coletividade. Por isso, ele se torna 'verdade' desse povo. Não é verdade comprovada em laboratório, mas a verdade de uma mentalidade coletiva. Ou seja: um mito sobrevive num povo não porque the explique sua realidade, mas por refletir um aspecto real desse mesmo povo, e até de todos nós $[\ldots]$. 
A (re)construção mítica de uma figura heroica se dá, sobretudo, pela construção e afirmação da "verdade", a partir das interpretações majoritárias dos sujeitos que compõem a sociedade, determinando, assim, o que é ser herói neste grupo. Na história da Argentina, Eva Perón teve uma importância política nunca antes pensada para uma mulher, pois, até então, elas nem votavam. Deixou o posto que normalmente é destinada a mulher do presidente, - restrito às celebrações oficiais como acompanhante, ou sonhando muito, as causas sociais - para tornar-se quase independente de Perón e reconhecida por seus próprios atos.

Eva Duarte conseguiu, em muito pouco tempo, sair do anonimato de uma vida de pouco glamour, como atriz, para o reconhecimento internacional. Tudo isso se deu de forma rápida e breve, como também foi sua vida. Morreu cedo, com somente trinta e três anos, gozando de plena popularidade, que era alavancada por um sistema de marketing pessoal muito eficiente com doações de dinheiro, casas e vestidos de noiva, entre outros presentes aos "grasitas", que era como ela chamava aos pobres, conforme expõe Sánchez (1997).

Por fim, após sua morte, teve seu corpo embalsamado a mando de Perón para que o povo argentino jamais a esquecesse. Todos esses fatos converteram Evita em uma personagem histórica excepcional, um mito que foi, intensamente, recriado pela ficção. Assim também aconteceu em Santa Evita (1996), o mito é recriado e reforçado na narrativa que se sustenta no corpo morto, mumificado e andarilho de Eva.

Tece-se a (re)construção mítica de Eva Perón no romance de Martínez harmoniosamente, fazendo confluir a documentação histórica com a construção do espaço ficcional. Nele, a diegese se embrenha pelo interior da existência das personagens que se transformam no centro da narrativa e se sobrepõem aos fatos históricos. De todas as personagens, o cadáver de Eva é a fundamental, e as outras apenas estão como coadjuvantes. Confirma-se, desse modo, a afirmação de Albuquerque e Fleck (2015), em que nos mostram os fios narrativos que compõem a elaboração do romance de Martínez:

[...] há nele três fios narrativos que relatam fatos diferentes de um mesmo tópico - a trajetória de Eva Perón. Enquanto um fio conta sua biografia (ao revés), o outro relata os percalços do seu corpo embalsamado. Essas narrativas encontram-se 'costuradas' pelo terceiro fio, que nada mais é que o relato de como essas narrativas estão sendo construídas pelo autor-narrador e as reflexões sob tal processo. A retirada desse terceiro fio narrativo da obra acarretaria em um total empobrecimento da narrativa e do próprio projeto estéticoliterário. Dá-se assim, sua constituição de metaficção historiográfica. (ALBUQUERQUE; FLECK, 2015, p. 49).

Nessa obra, Tomás Eloy Martinez adota o procedimento de posicionar-se como narrador-personagem dos acontecimentos históricos. Narrador de uma ficção que vai reinventando a história, e personagem de um romance que reconstrói os passos de criação de uma ficção. Esse processo autorreferencial se faz visível através da metaficção, e que na nossa análise terminou por reforçar o mito de Evita no romance e 
mais uma vez na ficção. O escritor conta a história reinventando os fatos, partindo de várias testemunhas que aparecem na obra como fontes de informação. São pessoas que, historicamente, estiveram direta ou indiretamente envolvidas com Eva. As primeiras são aquelas personagens que conheceram Evita pessoalmente, como o mordomo, sua mãe Juana Ibarguren -, Juan Domingo Perón; do segundo grupo fazem parte aquelas que tinham contato com outras pessoas que conviviam com Eva, como, Aldo Cifuentes, que foi uma das personagens que deu informações do coronel Koening, pois no momento da coleta dos dados já estava morto.

Os dois grupos são as fontes principais de informações, não únicas, pois há citações no rodapé das páginas - recurso metaficcional - que se remetem aos jornais e outros periódicos que são utilizadas como documentos "comprobatórios" das informações romanescas. Contudo, o essencial do romance é fornecido pelas personagens históricas que, na narrativa, tornam-se como todas nesse espaço, fictícias.

O fato de Martínez citar a fonte de sua pesquisa e, ainda, afirmar que as personagens históricas deram seus depoimentos não pode nos levar a, ingenuamente, crer na ficção como "verdade". A explicação é simples, Santa Evita (1996) é um romance. Por isso, uma obra ficcional, ainda que tenha suas raízes no real, não está comprometida com ela. Isso lhe dá "permissão" para alterar, manipular, omitir ou reinventar os fatos, segundo interesse ou necessidade da obra, como reconhece a própria vOz narrativa do romance ao explicitar que "[...] mito e história se bifurcam, ficando no meio o reino indestrutível e desafiante da ficção.” (MARTíNEZ, 1996, p. 313).

Assim, quando afirmamos em nosso estudo que os testemunhos são a base deste romance, não é para atribuir a obra "veracidade", pois ainda, seguindo as afirmações do autor de Santa Evita (1996), "todo relato é, por definição, infiel. A realidade, como já disse, não pode ser contada nem repetida. A única coisa que se pode fazer com a realidade é inventá-la de novo." (MARTÍNEZ, 1996, p. 84).

$\mathrm{O}$ intuito do narrador é mostrar, pelo emprego de recurso metaficcionais, como se deu o processo de construção da metanarrativa, porque, no nosso entendimento, este processo acaba por reforçar o mito de Eva Perón pelos relatos apaixonados de uma história mágica, de um corpo que é embalsamado para tornar-se imortal, e que se converte em objeto de desejo e prazer para seus guardiões, inclusive, àqueles que a odeiam, como se percebe no fragmento a seguir:

Durante meses o Coronel se atormentou por ter deixado Evita partir. Nada fazia sentido sem Ela. Quando bebia (e a cada noite de solidão ele bebia mais), percebia que era uma estupidez continuar a levá-la de um lugar para o outro. Por que tinha de entregá-lo a pessoas desconhecidas para que cuidassem dela? Por que não a deixavam com ele, que iria defendê-la melhor do que ninguém? (MARTÍNEZ, 1996, p. 219).

Os relatos, das personagens, que foram recriados na obra de Martínez são marcados pela emotividade, o que é característico daqueles que estão envolvidos, emocionalmente, em acontecimentos quaisquer da personagem em questão - o corpo morto de Eva - e, por isso, não conseguem desvincular-se afetivamente para fazer um 
relato sem prejuízo do fundamental e do objetivo. Isso se evidencia, na fala da personagem Julio Alcaraz, cabeleireiro oficial de Evita, quando fala dela à personagem Tomás Eloy:

Ela sabia que, mais cedo ou mais tarde, todo poder tem seu eclipse e queria viver em um ano as experiências que para os outros levam uma vida inteira. Negava-se a dormir. Telefonava para seus auxiliares às três da manhã para lhe dar ordens e tornava a telefonar para saber se tinham sido cumpridas. Num abrir e fechar de olhos urdiu uma rede de ministros, espiões e puxa-sacos que a mantinham a par de tudo o que acontecia no governo. Nisso era mais hábil que Perón; mas se ela se esmerou na trama não foi para lhe fazer sombra, como dizem, e sim porque no fundo ele era um frouxo. (MARTÍNEZ, 1996, p. 76).

Por meio dos testemunhos dessas "personagens históricas", o autor Tomás Eloy Martínez recria, ficcionalmente, os fatos que permeiam a vida e a morte de Evita. Para isso, reinventa a história "real", ou melhor, a versão da história conhecida; enfatizando o mito que significou Eva Perón e que até hoje "sobrevive" na Argentina: a vida de uma mulher que veio de uma aldeia muito humilde, que desde o nascimento teve muitos problemas e que são utilizados como alicerce para o nascimento do mito.

O percurso que a personagem histórica de fato fez, de sair do nada, de um lugarejo pobre para a capital Buenos Aires, a história de amor que uniu Eva e Perón era como das fábulas, a ajuda financeira aos pobres, foi um salto que surpreendeu a todos que a conheceram quando era somente uma medíocre atriz. Tais aspectos, incorporados à ficção, dão realce à personagem:

[...] Antes, por mais base e ruge que a gente colocasse, já se via de longe que ela era uma ordinária. Ninguém conseguia lhe ensinar a se sentar com elegância, nem a usar os talheres direito, nem a comer de boca fechada. Não deviam ter se passado quatro anos a vi de novo, e nem lhe digo. Uma deusa. As feições tinham se refinado tanto que ela exalava uma aura de aristocracia e uma delicadeza de contos de fadas. [...]. (MARTÍNEZ, 1996, p. 12).

Todos esses fatos da vida real de Eva são inseridos no romance para reforçar seu esforço em ser algo superior e enaltecer suas conquistas pessoais. Com todos esses elementos biográficos, não é de surpreender que uma pessoa conseguiu mobilizar uma nação. Evita saiu do anonimato para o reconhecimento nacional e até internacional. Mas sua trajetória foi interrompida por uma morte prematura, precedida por um fim agonizante que foi acompanhado por toda uma nação. Isso, de certa forma, serviu para engrandecer as realizações de Eva Perón. Ao contrário do que acontece com as pessoas "normais" que são esquecidas depois de mortas, no caso de Evita, o interesse popular cresceu e sua capacidade de mobilizar seguidores se ampliou após o falecimento. Tais circunstâncias da realidade são levadas à ficção, como podemos observar abaixo:

Morta - disse -, essa mulher é mais perigosa do que quando estava viva. O tirano sabia muito bem o que estava fazendo quando a deixou aqui, para nos infernizar a vida. Em qualquer buraco aparecem as fotos dela. Os ignorantes a veneram como se fosse uma 
santa. Acreditam que mais dia, menos dia ela vai ressuscitar para fazer da Argentina uma ditadura de mendigos. (MARTíNEZ, 1996, p. 22-23).

Por todos esses fatos apresentados e por outros mais, Evita se transmutou em um mito que até hoje, depois de mais de sessenta anos de seu falecimento, continua aguçando o interesse de muitos escritores que tentam reconstruir sua vida, e, também, pela história incomum de seu corpo, a trajetória que teve seu cadáver desde que desapareceu, em 1955, até voltar à Argentina, em 1971.

Se não é possível divulgar uma versão oficial que não deixe margem de dúvidas, que impossibilite aos escritores de usar sua liberdade expressiva, haverá, sempre, a possibilidade de contar a história de outra maneira.

Por isso, encontraremos muitas obras, tanto literárias como fílmicas, que se referem à vida de Eva Perón. No livro Evita - mitos y representaciones existe um artigo de Nina Gerassi Navarro em que há uma citação importante sobre estas produções:

Bajo el velo de reconstruir la vida de Eva Perón, esta colección de musical, docudrama y documentales se destaca por el modo en que cada una insiste en desentrañar una parte del enigma de su extraordinaria vida. Desentrañar, en otras palabras, la verdadera Evita, desarticular su mito. (NAVARRO, 2002, p. 6667).

O que se percebe é que todas as obras que retratam algo que esteja relacionado à vida de Eva Perón, inclusive o romance Santa Evita (1996) - ainda que sendo ficcional tentam aclarar o que é "a verdadeira Evita". Contudo, no resultado final, apenas retomam as cenas chaves da vida de Eva Perón, que se repetem, sistematicamente, em todas as obras acerca de sua vida, como: a ilegitimidade, uma infância pobre, o sonho de ser atriz, o casamento com Perón e sua incursão na vida política, e, por fim, sua trágica morte em plena juventude que seduziu o imaginário coletivo. Estas imagens, já amplamente conhecidas, convertem-se em marcos necessários para legitimar a (re)construção de sua vida e o vínculo da produção com a história.

Navarro ainda aponta que,

[...] la bistoria en estos casos se popularizan, se traducen para un público amplio, para reconfigurarla en una biografía envuelta en imágenes y anécdotas sensacionalistas. [...] tanto las recreaciones ficticias de vida de Eva Perón como los documentales sostienen revelar una verdad y como tal buscan colocarse dentro de los parámetros de la bistoria. Estas versiones parten de una historia supuestamente conocida a la que agregan, según el caso, datos que ayudarian a dar una imagen más definitiva de la verdadera Evita. (NAVARRO, 2002, p. 67).

Essas afirmações são encontradas em obras que abordam fatos da esposa de Juan Domingo Perón. A (re)construção mítica nesse romance ocorre a partir de uma construção feita alicerçada em histórias já contadas - como anteriormente mencionado - da vida da personagem-protagonista.

Por tudo isso se afirma que em Santa Evita (1996) não há superação do mito, mas, sim, sua reafirmação consciente através da exposição dos extremos antagônicos de sua história "real", que são apresentados aos leitores, na maioria das vezes, quando alguém 
se propunha a falar de Eva Perón: 1 - por um lado a mulher dedicada, adorada que daria a vida pelo povo, uma verdadeira santa; 2 - do outro extremo, a imoral que usava os homens por meio do sexo para controlar e ascender publicamente, uma meretriz.

A primeira faceta é apresentada em Santa Evita (1996) pelos relatos testemunhais das personagens que seguem descrevendo uma Eva apaixonada pelas causas sociais e do povo argentino. Já a segunda imagem de Evita é percebida na narrativa pelo encanto que seu corpo exerce nos demais, induzindo-os, ainda que seja um cadáver.

A respeito do que já foi dito, filmado ou escrito sobre Eva Perón, existe um ponto em comum nos levantamentos acerca de sua trajetória, como expôs Sánchez (2002, p. 53): "de algun modo, y esto se equipara la mayoría de los relatos, [...] resulta el momento culminante e inevitable en la vida de un ser excepcional destinado a ser mito." (SANCHÉZ, 2002, p. 53). O mito é constantemente reafirmado nas produções relacionadas à Eva Perón através da ideia que aparece em todas as obras: de que, apesar de todas as dificuldades, Evita resiste e supera a tudo. Santa Evita (1996) ratifica o mito porque assevera que, apesar de todas as dificuldades vivenciadas desde a infância, ela conseguiu êxito pessoal e além da trajetória incomum que padeceu seu corpo, Evita resiste.

Tomás Eloy Martinez, o autor, além de narrar conforme explicado acima, ainda usa uma estratégia interessante para contar os últimos dias da vida de Eva Perón e a trajetória de seu corpo. Ele se posiciona como narrador-personagem da história e a partir disso reconstrói, ficcionalmente, os passos de criação da obra, imprimindo-lhe a essência da metaficção. Tudo isso, com a ajuda dos testemunhos das personagens reais que se tornaram fictícias na narrativa.

Isso ocorre porque as pessoas reais - representadas na obra -, segundo Navarro (2002), estão influenciadas pelo mito Evita e, portanto, não conseguem uma análise mais completa de seu real valor para a Argentina, prendendo-se à superficialidade dos fatos,

[...] en su afán por reconstruir y explicar un mito, caen justamente en la creación de un mundo en el que no existe nada más allá de lo inmediatamente visible del mismo mito. En lugar de partir de la historia para entender al mito, [...] parten del mito - construido desde la bistoria - y vuelven a la historia justamente para sostener el mito. (NAVARRO, 2002, p. 100).

Santa Evita (1996) parte de fatos relacionados à Evita indivíduo para explicar os fatos que rodearam sua vida. A complexidade do período histórico pelo qual passava a Argentina é exposta, partindo da posição em que a protagonista teve influência decisiva no processo. Tal período determinou a importância histórica que a mesma assumiu.

Esses pontos, entrelaçados a uma história sustentada por um cadáver que fascina aos demais, reforça o mito de uma mulher que conseguiu reunir em torno de si uma legião de adoradores e de inimigos.

\section{REFERENCIAS BIBLIOGRÁFICAS}

ALBUQUERQUE, Adenilson Barros; FLECK, Gilmei Francisco. Canudos: conflitos além da guerra - entre o multiperspectivismo de Vargas Llosa (1981) e a mediação de Aleilton Fonseca (2009). Curitiba, PR: CRV, 2015. 
ELIADE, Mircea. Mito e Realidade. São Paulo: Perspectiva, $3^{a}$ edição. 1991

FEIJÓ, Martín Cezar. O que é herói. São Paulo: editora Brasiliense, Coleção Primeiros Passos. 1984

FLECK, Gilmei Francisco. A conquista do "entre-lugar": a trajetória do romance histórico na América. Gragoatá, Niterói, n. 23, p. 149-167, jul./dez. 2007.

Gêneros híbridos da contemporaneidade: o romance histórico contemporâneo de mediação - leituras no âmbito da poética do descobrimento. In: RAPPUCCI, C.A; CARLOS, A. M. (Orgs.). Cultura e Representação - ensaios. Assis/SP: Triunfal, 2011. p. $81-95$.

GOMES, Anderson Soares. Narrando Fatos: História e Historicidade em O Homem do Castelo de Philip K. Dick. VIII. Congresso Nacional de Lingüística e Filologia Cadernos do CNLF, Série VIII, $\mathrm{n}^{\circ} 07$, 2004. Disponível em: http://www.filologia.org.br/viiicnlf/anais/caderno07-08.html_acesso dez. 2005.

HUTCHEON, Linda. Poética do Pós-modemismo: História, Teoria, Ficção.Trad. Ricardo Cruz. - Rio de Janeiro: Imago Ed., 1991. 330p.

JAMESON, Fredric. Pós-modernismo: A lógica cultural do capitalismo tardio. Tradução de Maria Elisa Cevasco. São Paulo: Ática, 2a edição, 1997.

MAESTRI, Mário. História e romance histórico: fronteiras. Revista Novos Rumos, Marilia/SP, ano 17, n. 36, 2002. Disponível em: http://www2.marilia.unesp.br/revistas/index.php/novosrumos/article/viewFile/2228/ 1846. Acesso jul. 2016.

MARTÍNEZ, Tomás Eloy. Santa Evita. Trad. Sérgio Molina. São Paulo: Companhia das Letras, 1996.

MENTON, Seymour. La Nueva Novela Histórica De La América Latina, 1979-1992. México: Fondo de Cultura Económica, 1993.

NAVARRO, Nina Gerassi. Evita - Mitos y representaciones. Serie Breves. Argentina: Fondo de Cultura Económica, 2002.

SÁNCHEZ, Matilde. Evita - Imagens de uma Paixão. São Paulo: editora DBA Melhoramentos. 1997. 
VEYNE, Paul. Como se escreve a bistória e Foucault revoluciona a história. Trad. de Alda Baltar e Maria Auxiadora Kneipp. Brasília: UnB, 4. ed., 1998. Disponível em: http://histoeajuda.blogspot.com.br/2015/04/como-se-escreve-historia-pdf.html. Acesso jul. 2016.

VIU, Antonia. Una poética para el encuentro entre historia y ficción. Revista cbilena de literatura. Chile, $\mathrm{n}^{\circ}$ 70, 167-178. Abril 2007. Disponível em http://www.revistaliteratura.uchile.cl/index.php/RCL/article/viewFile/1451/1339. Acesso Set. 2016.

Recebido em: 29/03/2017 Aprovado em: 25/05/2017 Publicado em: 01/06/2017 